\title{
Apolipoprotein E Gene Polymorphisms Are Strong Predictors of Inflammation and Dyslipidemia in Rheumatoid Arthritis
}

\author{
TRACEY E. TOMS, JACQUELINE P. SMITH, VASILEIOS F. PANOULAS, HEATHER BLACKMORE, \\ KAREN M.J. DOUGLAS, and GEORGE D. KITAS
}

ABSTRACT. Objective. Rheumatoid arthritis (RA), a condition with a strong genetic etiology, is associated with
excess cardiovascular disease (CVD). Dyslipidemia in RA may be driven by inflammation and genetic
factors. Apolipoprotein E (ApoE) is important for the regulation of lipid levels and CVD risk and
immune function in the general population. We compared the frequency of 2 ApoE single-nucleotide
polymorphisms (SNP) in patients with RA and controls, and studied the relationship of ApoE genotypes
with lipids and inflammation in RA.

Methods. A total of 387 patients with well-characterized RA and 420 non-RA controls were studied. Two ApoE SNP, rs7412 (ApoE2) and rs429358 (ApoE4), were identified.

Results. Genotypic $(\mathrm{p}=0.908)$ and allelic $(\mathrm{p}=0.894)$ frequencies did not differ between RA and controls. Within RA, the E2 allele was associated with the lowest and E4 allele with the highest levels of total cholesterol $(p=0.007)$, low-density lipoproteins $(p=0.004)$, and apolipoprotein $B(p=0.009)$. The E4 allele was also associated with lower C-reactive protein $(\mathrm{p}=0.007)$, erythrocyte sedimentation rate $(\mathrm{p}=0.001)$, and Disease Activity Score $(\mathrm{p}=0.015)$ compared to the E3 allele. E2 or E4 alleles were not associated with CVD in RA, although a trend was observed $(\mathrm{p}=0.074)$.

Conclusion. The frequency of ApoE polymorphisms did not differ between patients with RA and controls. ApoE genotypes are strongly linked to inflammation and lipid levels in RA, raising interest in the prognostic implications of ApoE genotypes. (First Release Dec 15 2011; J Rheumatol 2012;39:218-25; doi:10.3899/jrheum.110683)

\section{Key Indexing Terms: \\ RHEUMATOID ARTHRITIS \\ SINGLE-NUCLEOTIDE POLYMORPHISMS}

\section{APOLIPOPROTEIN E
DYSLIPIDEMIA \\ APOLIPOPROTEIN E
DYSLIPIDEMIA}

Rheumatoid arthritis (RA) is a complex autoimmune disease that primarily presents with peripheral joint pain and swelling;

From the Department of Rheumatology, Dudley Group of Hospitals National Health Service (NHS) Trust, Russells Hall Hospital, Dudley, West Midlands; Arthritis Research UK Epidemiology Unit, Manchester University, Manchester; and Department of Clinical Biochemistry, Dudley Group of Hospitals NHS Trust, Russells Hall Hospital, Dudley, West Midlands, United Kingdom.

Supported by an Arthritis Research Campaign Clinical Fellowship grant (grant 18848 to Dr. Toms) and an Arthritis Research Campaign infrastructure support grant (grant 17682 to the Dudley Group of Hospitals NHS Foundation Trust, Department of Rheumatology). Dr. Panoulas is supported by a PhD Scholarship from Empirikion Institute, Athens, Greece.

T.E. Toms, MBChB (Hons), Department of Rheumatology, Dudley Group of Hospitals NHS Trust, ARC Epidemiology Unit, Manchester University; J.P. Smith, BSc (Hons), MSc, Department of Clinical Biochemistry, Dudley Group of Hospitals NHS Trust; V.F. Panoulas, MD, PhD, Department of Rheumatology, Dudley Group of Hospitals NHS Trust; H. Blackmore, BSc, Department of Clinical Biochemistry, Dudley Group of Hospitals NHS Trust; K.M.J. Douglas, MBChB, MD, Department of Rheumatology, Dudley Group of Hospitals NHS Trust; G.D. Kitas, MD, PhD, FRCP, Department of Rheumatology, Dudley Group of Hospitals NHS Trust, ARC Epidemiology Unit, Manchester University.

Address correspondence to Prof. G.D. Kitas, Department of Rheumatology, Dudley Group of Hospitals NHS Trust, Russells Hall Hospital, Pensnett Road, Dudley, West Midlands, DY1 2HQ, UK. E-mail:gd.kitas@dgoh.nhs.uk

Accepted for publication September 8, 2011. it is also associated with excess cardiovascular morbidity and mortality, which account for up to half of all RA deaths $s^{1,2,3}$. The pathogenesis of cardiovascular disease (CVD) in RA is multifactorial, involving traditional risk factors, such as hypertension $^{4,5}$, dyslipidemia ${ }^{6}$, obesity ${ }^{7,8}$, and physical inactivity ${ }^{9}$, as well as novel factors, including systemic inflammation ${ }^{10}$.

The lipid profile in RA is characterized by low levels of total cholesterol (TC), high-density lipoproteins (HDL), and low-density lipoproteins (LDL) ${ }^{11,12,13}$, and an increased atherogenic index (TC:HDL ratio) ${ }^{12,14,15}$. Systemic inflammation is thought to drive many of these changes through alterations in enzymatic activity and cytokine/acute-phase protein-mediated effects on lipid metabolism ${ }^{6}$. However, multiple other factors may also contribute. For example, in the general population genetic polymorphisms have been shown to be fundamental for both the regulation of lipid levels and the development of CVD $16,17,18,19,20,21,22$. In RA, a condition with a strong genetic etiology $23,24,25,26,27$, the frequency and role of genetic polymorphisms regulating lipid metabolism are unknown.

Apolipoprotein E (ApoE) is synthesized by the liver, in brain tissue, and by macrophages resident in atherosclerotic plaques, and is essential for the catabolism of triglyceride (TG)-rich lipoproteins ${ }^{28,29}$ and plays an important role in car-

Personal non-commercial use only. The Journal of Rheumatology Copyright @ 2012 . All rights reserved. 
diovascular disease $\mathrm{e}^{30}$ and immunoregulation ${ }^{31,32,33}$. Of particular interest, ApoE has been shown to affect macrophage oxidative status ${ }^{34}$ and inhibits $\mathrm{T}$ lymphocyte proliferation ${ }^{31}$. There are 3 different isoforms of ApoE (ApoE2, ApoE3, and ApoE4). ApoE3 is the parent form, while ApoE2 and ApoE4 occur as a result of 2 single-nucleotide polymorphisms (SNP) at residue 158 and 112, respectively ${ }^{35}$. These isoforms exhibit different pathophysiological/phenotypic properties in the general population: ApoE2 associates with lower serum ApoE, TC, and LDL levels, while ApoE4 produces the opposite effect, increasing serum ApoE, TC, and LDL levels, as well as CVD risk ${ }^{30}$. Although the alterations in the lipid profile can partly explain the link between ApoE and CVD, other mechanisms may also contribute. Serum ApoE levels are inversely associated with levels of high sensitivity C-reactive protein (hsCRP) in the general population ${ }^{36,37}$, a known independent risk factor for $\mathrm{CVD}^{38}$. The $\mathrm{E} 2$ allele associates with higher levels and the $\mathrm{E} 4$ allele with lower levels of $\mathrm{CRP}^{37}$.

In our study we aimed to assess the frequency of the ApoE genotypes in patients with RA versus healthy controls, and to assess the relationship of ApoE genotypes with lipid levels and systemic inflammation in patients with RA.

\section{MATERIALS AND METHODS}

Study populations. The study was approved by the local Research Ethics Committee and Research and Development Directorate and all participants gave written informed consent, according to The Declaration of Helsinki ${ }^{39}$.

For the purposes of this cross-sectional study, 2 populations were assessed. The first included 387 patients fulfilling the 1987 American College of Rheumatology criteria for $\mathrm{RA}^{40}$, recruited from routine rheumatology outpatient clinics held at the Dudley Group of Hospitals National Health Service Foundation Trust, between August 1, 2004, and July 31, 2006. The comparator population consisted of 420 local general population non-RA controls identified from a previously collected anonymized DNA biobank.

Data recorded on the patients with RA included basic demographics (age, sex, height, weight, waist circumference), a full medical history (including specific details regarding RA and CVD), current disease activity using the 28-joint Disease Activity Score (DAS28) ${ }^{41}$ and physical function using the Health Assessment Questionnaire (HAQ $)^{42}$. All current medications were documented, including antirheumatic drugs, analgesics, and cardiovascular drugs such as statins and antihypertensives. All patients with RA also gave fasting blood samples for routine tests including full blood count, urea and electrolytes, liver function, CRP, erythrocyte sedimentation rate (ESR), lipid profile, and thyroid function tests. Estimated glomerular filtration rate (eGFR) was calculated according to the Modification of Diet in Renal Disease equation ${ }^{43}$. Detailed descriptions of the RA population have been published by our group ${ }^{44,45}$. CVD was defined as a positive history of any of the following: myocardial infarction, angioplasty, coronary artery bypass grafting, peripheral vascular disease, stroke or transient ischemic attack, or positive Rose questionnaire ${ }^{46}$ on assessment. Dyslipidemia was defined by the US National Cholesterol Education Program guidelines: i.e., TC $\geq 6.2$ $\mathrm{mmol} / 1$ or $\mathrm{HDL}<1.03 \mathrm{mmol} / 1$ or $\mathrm{LDL} \geq 4.13 \mathrm{mmol} / \mathrm{l}$ or $\mathrm{TG} \geq 1.7 \mathrm{mmol} / \mathrm{l}^{47}$. Data available on the local population controls were limited to age and sex. All subjects provided DNA samples stored for subsequent genetic analysis.

Genotyping. The 2 ApoE SNP were identified simultaneously using the Roche LightCycler 480 System and a Roche ApoE mutation detection kit (cat. no. 03004716001). Polymerase chain reaction was performed with a reaction volume of $20 \mu 1$ containing $2 \mu 1$ DNA, $12 \mu 1$ sterile water, $2 \mu 1$ Lightcycler reaction mix, and $4 \mu 1$ Lightcycler ApoE mutation detection mix containing an anchor probe specific for both codons 112 and 158, labeled at the 3' end with fluorescein, and 2 sensor probes specific for codons 112 and 158 labeled at the 5' end with Lightcycler Red 640 and Lightcycler Red 705, respectively.

The cycle conditions were as follows: 1 cycle of $95^{\circ} \mathrm{C}$ for $10 \mathrm{~min}$, programmed ramp rate of $4.4^{\circ} \mathrm{C} / \mathrm{s} ; 35$ cycles of $95^{\circ} \mathrm{C}$ for $6 \mathrm{~s}, 53^{\circ} \mathrm{C}$ for $15 \mathrm{~s}$, and $72^{\circ} \mathrm{C}$ for $10 \mathrm{~s}$ each with a temperature transition rate of $4.4^{\circ} \mathrm{C} / \mathrm{s}, 2.2^{\circ} \mathrm{C} / \mathrm{s}$, and $4.4^{\circ} \mathrm{C} / \mathrm{s}$, respectively; then melting curve analysis for 1 cycle of $95^{\circ} \mathrm{C}$ for $5 \mathrm{~s}$ and $40^{\circ} \mathrm{C}$ for $30 \mathrm{~s}$, each with a transition temperature rate of $4.4^{\circ} \mathrm{C} / \mathrm{s}$ and $2.2^{\circ} \mathrm{C} / \mathrm{s}$, respectively, and then rising to $75^{\circ} \mathrm{C}$ at $0.11^{\circ} \mathrm{C} / \mathrm{s}$, continuous with 5 acquisitions per $1^{\circ} \mathrm{C}$. By combining the melting curve analysis from the genotyping of codon 112 and codon 158 the allelic structure of the analyzed samples was determined, e.g., E2E2 (Table 1).

A negative (water) control and a positive heterozygous control were included in each run.

Statistical analysis. Data analysis was carried out using SPSS 15.0 (SPSS Inc., Chicago, IL, USA).

Genotype and allele frequencies were compared using the chi-square test in the total populations, before and after adjustment for age and sex. The Kolmogorov-Smirnov test was used to establish the distribution of each parameter. The variation of clinical characteristics across the genotypes was analyzed using chi-square, ANOVA, and Kruskal-Wallis tests for categorical, normally distributed, and non-normally distributed variables, respectively. ANCOVA was used to assess the association between lipid and inflammatory variables with the different genotypes and all results were adjusted for multiple comparisons.

When analyzing the association of ApoE genotypes with lipid levels and inflammatory markers, patients receiving lipid-lowering therapy, e.g., statins, were excluded due to the confounding effects of such treatment on lipid levels and inflammatory markers. In addition, the E2E4 genotype was excluded due to its potential to exert mixed phenotypic effects relating to the E2 and E4 allele.

The study had $80 \%$ power at the $5 \%$ significance level to detect a $6 \%$ difference in the prevalence of the rs 7412 genotype and a $7 \%$ difference in the prevalence of the rs 429358 genotype between RA and controls. Within patients with RA, the study had $80 \%$ power at the $5 \%$ significance level to detect a difference of at least $0.52 \mathrm{mmol} / \mathrm{l}$ in TC and $0.53 \mathrm{mmol} / \mathrm{l}$ in LDL between the $\mathrm{E} 2$ and $\mathrm{E} 3$ alleles, and a difference of $0.42 \mathrm{mmol} / \mathrm{l}$ in TC and 0.41 $\mathrm{mmol} / \mathrm{l}$ in LDL between the E4 and E3 alleles. For non-normally distributed variables the values were logged; this demonstrated that the study had $80 \%$ power at the 5\% significance level to detect a difference of $13.2 \%$ in HDL, $21.3 \%$ in TG, $52.1 \%$ in CRP, and $53.5 \%$ in ESR between the E2 and E3 alleles, and a difference of $10.2 \%$ in HDL, $16.1 \%$ in TG, $38 \%$ in CRP, and $39.3 \%$ in ESR between the E4 and E3 alleles.

\section{RESULTS}

Genotypic and allelic frequencies of the ApoE gene. Patients with RA were significantly older than the controls $(\mathrm{p}<0.001)$, with a median age of 62.2 years [interquartile range (IQR) 53-69.1] compared to 51 years (IQR 39.75-61), respectively.

Table 1. Assignment of genotypes following combination of the melting curves from rs7412 (ApoE2) and rs429358 (ApoE4).

\begin{tabular}{lcc}
\hline $\begin{array}{l}\text { Genotype of Codon 112 } \\
\text { (ApoE2) }\end{array}$ & $\begin{array}{c}\text { Genotype of Codon 158 } \\
\text { (ApoE4) }\end{array}$ & Allelic Setup \\
\hline TGC/TGC & TGC/TGC & E2/E2 \\
TGC/TGC & CGC/CGC & E3/E3 \\
CGC/CGC & CGC/CGC & E4/E4 \\
TGC/TGC & CGC/TGC & E2/E3 \\
CGC/TGC & CGC/TGC & E2/E4 \\
CGC/TGC & CGC/CGC & E3/E4 \\
\hline
\end{tabular}

ApoE: apolipoprotein E. Personal non-commercial use only. The Journal of Rheumatology Copyright @ 2012 . All rights reserved. 
Sex distribution also differed, with a higher proportion of females among patients with RA (73\% vs $60.1 \%$; p < 0.001 ). The ethnic split of the 2 populations was comparable, with 97\% of patients with RA and $97.2 \%$ of controls being white.

The genotypic $(\mathrm{p}=0.908$; Table 2$)$ and allelic frequencies (E2, 59 vs 64; E3, 604 vs 659; E4, 111 vs 117 ; p = 0.894) were not different between patients with RA and controls, and remained so following adjustment for age and sex $(p=0.910$ and $\mathrm{p}=0.900$, respectively). Genotype frequencies were found to be in Hardy-Weinberg equilibrium.

Differences in clinical characteristics of patients with $R A$ according to ApoE allele (Table 3). Age ( $\mathrm{p}=0.061)$ and sex $(\mathrm{p}=0.331)$ did not significantly differ according to the presence of the E2 or E4 allele. Methotrexate use was significantly lower in patients with the E2 allele compared to those with the $\mathrm{E} 3$ or E4 allele (39.5\% vs $62.5 \%$ vs $60.3 \%$, respectively; $\mathrm{p}=0.021)$. Dyslipidemia was least prevalent in patients with the E2 allele and highest in patients with the E4 allele (E2, $33 \%$ vs E3, $61.2 \%$ vs E4, 73.1\%; p < 0.001). No significant differences were observed in the prevalence of other CVD risk factors such as hypertension $(\mathrm{p}=0.537)$, diabetes mellitus $(\mathrm{p}=0.962)$, body mass index $(\mathrm{BMI} ; \mathrm{p}=0.739)$, or smoking $(\mathrm{p}=0.596)$. The metabolic syndrome (defined by the 2009 joint consensus criteria ${ }^{48}$ ) was lower in patients with 1 or more E2 or E4 alleles than in the parent form, E3E3 [E2, 18 (10.5\%), E4, 54 (31.4\%) vs E3E3, 100 (58.1\%); p = 0.035]. Prevalent CVD did not differ across the genotypes $(\mathrm{p}=$ 0.970). However, if high-risk patients (those receiving lipid-lowering therapy) were included in the analysis, a trend was observed with the prevalence of CVD lowest among patients with the $\mathrm{E} 2$ allele and highest among patients with the E4 allele (E2, 16.3\% vs E3, 20.4\% vs E4, 28.1\%; $\mathrm{p}=0.074$ ).

Association between ApoE alleles and lipid levels in RA. Univariate analyses demonstrated significant differences in lipid levels according to the ApoE allele present (Figure 1). TC (p < 0.001), LDL ( $p<0.001)$, and ApoB ( $=0.004)$ were all lower in patients with the E2 allele (E2E3, E2E2) compared to those with the parent E3 allele (E3E3). ApoB levels were significantly higher in patients with the $\mathrm{E} 4$ compared to the E3 allele ( $p=0.034)$, with a trend for LDL also to be higher among patients with the E4 compared to the E3 allele ( $\mathrm{p}=$ 0.066; Table 3).

Table 2. Frequency of apolipoprotein E (ApoE) genotypes in patients with rheumatoid arthritis (RA) and healthy controls.

\begin{tabular}{lccc}
\hline $\begin{array}{l}\text { ApoE } \\
\text { Genotype }\end{array}$ & $\begin{array}{c}\text { RA Patients, } \\
\mathrm{n}=387\end{array}$ & $\begin{array}{c}\text { Healthy Controls, } \\
\mathrm{n}=420\end{array}$ & $\mathrm{p}$ \\
\hline E2E2, n (\%) & $3(0.8)$ & $5(1.2)$ & \\
E2E3, n (\%) & $46(11.9)$ & $48(11.4)$ & \\
E2E4, n (\%) & $7(1.8)$ & $6(1.4)$ & 0.908 \\
E3E3, n (\%) & $235(60.7)$ & $262(62.4)$ & \\
E3E4, n (\%) & $88(22.7)$ & $87(20.7)$ & \\
E4E4. n (\%) & $8(2.1)$ & $12(2.9)$ & \\
\hline
\end{tabular}

After adjustment for potential confounders [age, sex, RA characteristics (CRP, HAQ, rheumatoid factor status), BMI, glucose levels, and antirheumatic medication (methotrexate, sulfasalazine, hydroxychloroquine, leflunomide, anti-tumor necrosis factor therapy, prednisolone)] in a general linear model, TC ( $\mathrm{p}=0.001)$, LDL ( $\mathrm{p}=0.009)$, and ApoB ( $\mathrm{p}=$ $0.001)$ levels remained significantly lower in patients with the E2 allele (E2E3, E2E2), while LDL $(p=0.009)$ and ApoB $(\mathrm{p}=0.009)$ remained significantly higher in patients with the E4 allele (E3E4, E4E4) compared to those with the E3 (E3E3) allele (Table 4).

These findings were replicated in allele dose analyses.

Associations between ApoE alleles and inflammatory markers. Univariate analyses demonstrated that E4 heterozygotes (E3E4) or homozygotes (E4E4) had significantly lower levels of CRP ( $p=0.005)$, ESR ( $p=0.002)$, and DAS28 scores ( $p=$ 0.024) compared to patients with the E3 (E3E3) allele. No significant differences in CRP, ESR, or DAS were found between the E2 and E3 alleles. However, allele dose analyses not only confirmed the above findings for the E4 allele but also demonstrated CRP to be significantly higher among patients with 1 or more E2 alleles compared to patients with no E2 alleles $(\mathrm{p}=0.009)$.

After adjustment for potential confounders [age, sex, RA characteristics (HAQ, rheumatoid factor status), and medication (methotrexate, sulfasalazine, hydroxychloroquine, leflunomide, anti-tumor necrosis factor therapy, prednisolone)] in a general linear model, lower CRP $(p=0.007)$, ESR $(p=0.001)$, and DAS28 scores $(p=0.015)$ remained significantly associated with the E4 allele (Table 4). The association of the E2 allele with CRP in the allele dose-dependent analysis remained significant following adjustment for potential confounders $(\mathrm{p}=0.044)$. No significant differences in ESR or DAS28 were found between the E2 and E3 allele.

Analysis of the data was repeated following the exclusion of data for ethnic minorities; however, the results remained unchanged (data not shown).

\section{DISCUSSION}

To our knowledge, this is the first study to assess the frequency and role of ApoE genotypes in patients with RA. We did not find significant differences in the frequency of ApoE genotypes between patients with RA and local population controls, but as expected from general population studies, ApoE genotypes were major determinants of lipid levels in patients with RA, too. We also demonstrate for the first time in a "high-grade" inflammatory condition, i.e., RA, that ApoE genotypes associate with the intensity of inflammation. The overall influence of ApoE genotypes on both articular and cardiovascular outcomes in RA requires further study.

For decades, lipid levels have been shown to be predictive of CVD risk ${ }^{49,50,51}$ and are widely used in CVD risk algorithms ${ }^{47,52,53}$. Our study demonstrates that ApoE genotypes are strongly linked to lipid levels in RA. The effects of the 
Table 3. Clinical characteristics across the ApoE alleles (excluding patients taking statins). Results expressed as percentages, median (25th-75th percentile values), or mean $\pm \mathrm{SD}$ as appropriate.

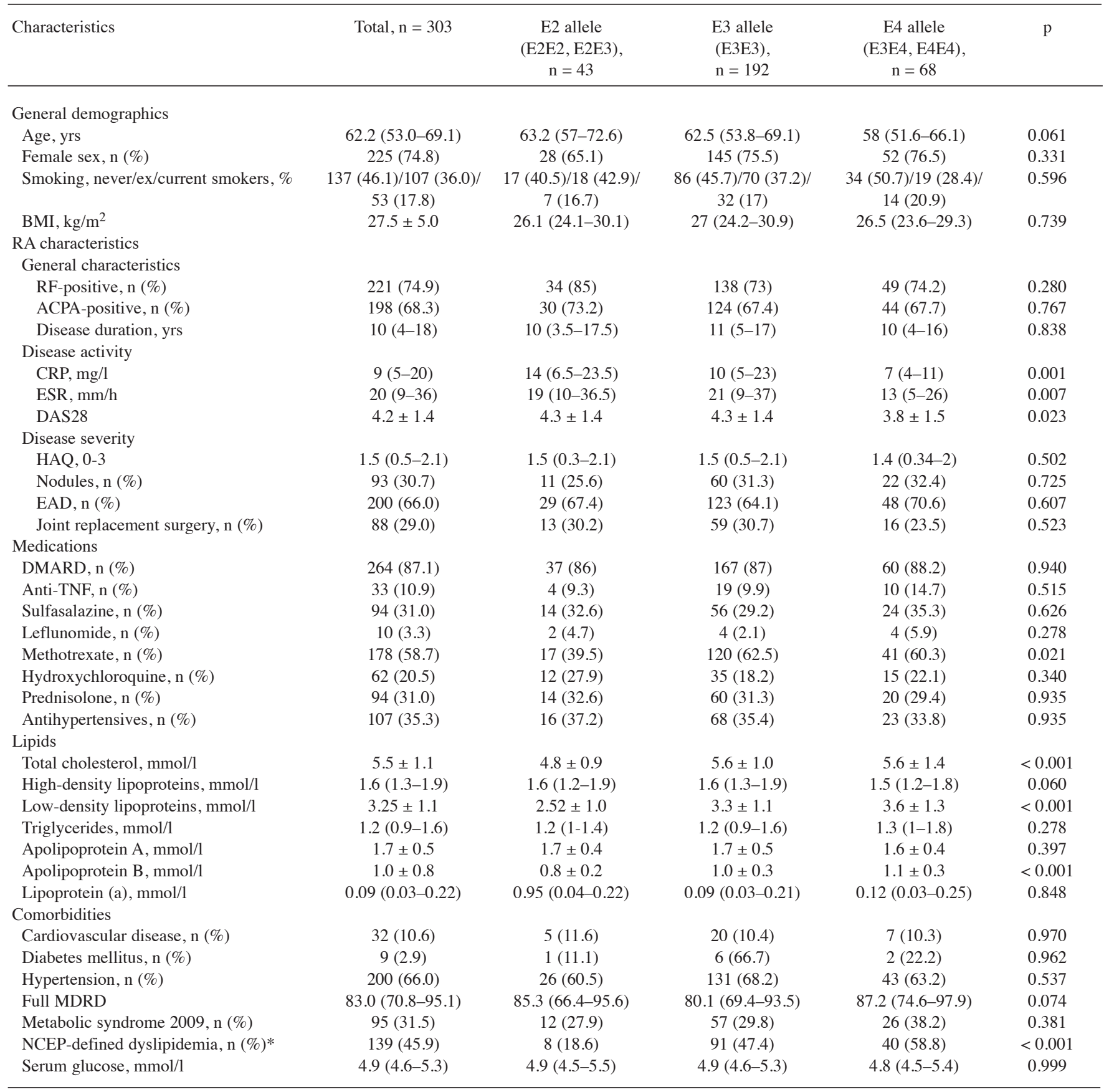

ApoE: apolipoprotein E; RA: rheumatoid arthritis; BMI: body mass index; RF: rheumatoid factor; ACPA: anticitrullinated protein antibodies; CRP: C-reactive protein; ESR: erythrocyte sedimentation rate; DAS28: Disease Activity Score; HAQ: Health Assessment Questionnaire; EAD: extraarticular disease; DMARD: disease-modifying antirheumatic drugs; anti-TNF: anti-tumor necrosis factor; Full MDRD: modification of diet in renal disease; NCEP: US National Cholesterol Education Program. * Total cholesterol $\geq 6.2$ or triglycerides $\geq 1.7 \mathrm{mmol} / \mathrm{l}$ or low-density lipoprotein $\geq 4.13 \mathrm{mmol} / \mathrm{l}$ or high-density lipoprotein $<1.03 \mathrm{mmol} / \mathrm{l}$.

genotypes are similar to those seen in the general population, with the E2 allele associated with low levels of TC and LDL and the E4 allele associated with high levels of TC and LDL. Interestingly, one study has reported that the effects of ApoE on regression of atherosclerosis occurs independently of changes in lipid levels ${ }^{54}$. Irrespective of this we found that RA patients harboring the E4 allele are twice as likely to have dyslipidemia as those with the E2 allele, thus potentially increasing their risk for CVD.

Inflammation is fundamental to all stages of atherosclerotPersonal non-commercial use only. The Journal of Rheumatology Copyright $\subset$ 2012. All rights reserved. 
A

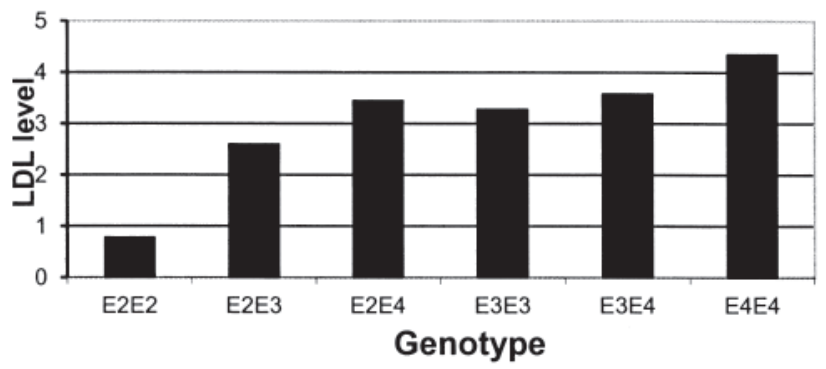

C

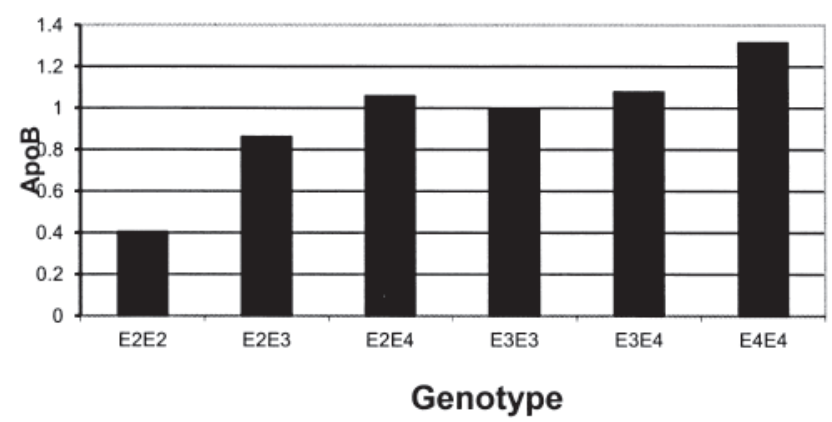

B

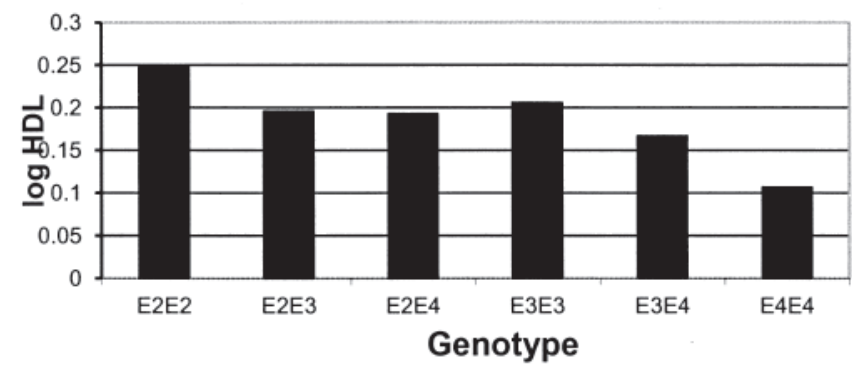

D

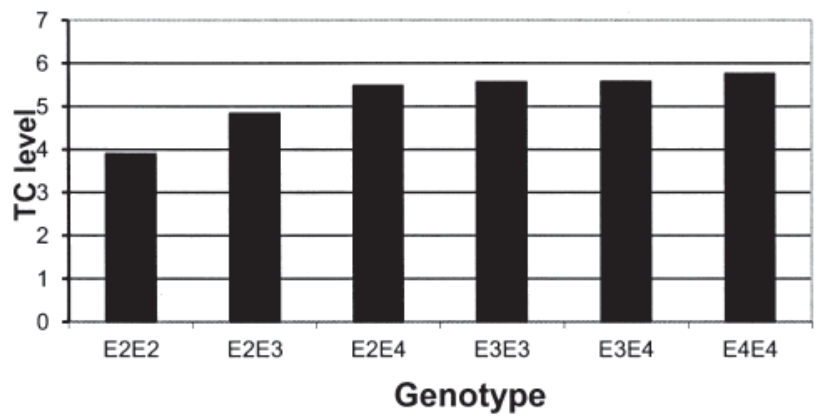

Figure 1. Lipid levels across the apolipoprotein E (ApoE) genotypes in patients with rheumatoid arthritis (excluding patients receiving statins). A. Low-density lipoprotein levels according to genotype. B. High-density lipoprotein levels according to genotype. C. ApoB levels according to genotype. D. Total cholesterol levels according to genotype.

ic plaque formation ${ }^{10}$ and is now recognized as an independent CVD risk factor $^{38}$. ApoE is known to play a key role in "low-grade" subclinical inflammation $55,56,57$; however, its role in the context of high-grade systemic inflammation had not previously been studied. The association between ApoE genotypes and inflammatory markers appears to be amplified in RA. However, the pattern of allelic association mirrors that observed in the general population, with the E2 allele predicting the highest and the E4 allele the lowest CRP levels ${ }^{57}$. In RA, CRP is an important marker of disease activity and severity, thus it is possible that these ApoE genotypes may also have prognostic value for arthritis and functional outcomes. DAS28 and ESR were also significantly lower in patients with the E4 allele compared to the E2 or E3 allele, but there were no significant associations between ApoE genotypes and other markers of disease severity (HAQ scores or number of joints replaced). This may be due to lack of power to detect such associations. Further specifically designed studies are required to assess the effects of the ApoE genotypes on markers of disease severity and progression, for example, progression of erosive damage.

In the general population, it is well described that the E4 allele increases CVD risk ${ }^{30}$; whether the E2 allele is "protective" is less clear ${ }^{16}$. ApoE genotypes did not significantly associate with prevalent CVD in this RA cohort, probably due to insufficient power, but a trend was observed $(\mathrm{p}=0.074)$. It is still feasible that polymorphisms of the ApoE gene contribute to atherosclerotic plaque formation in RA through inflammation-mediated suppression of gene transcription. At the level of the atherosclerotic plaque, ApoE is primarily produced by macrophages and it exerts antiatherogenic properties by facilitating reverse cholesterol transport. Interestingly, a recent study using lipopolysaccharide (LPS) treatment to mimic inflammatory stress has demonstrated that LPS levels repress ApoE gene expression in macrophages through its effects on inflammatory signaling pathways ${ }^{58}$. Such mechanisms are likely to be escalated in RA as a consequence of high levels of systemic inflammation, and this should be addressed in specifically designed studies.

The strengths of our study include the detailed clinical and laboratory characterization of patients with RA and use of a local control group for the genetic comparisons. The most important limitation of the study is its cross-sectional design, which does not allow definitive interpretation of the causality and directionality of the associations found. Due to the single timepoint data collection, we were unable to take into account biological variations in inflammatory or lipid measures that may also have affected the results. In addition, although this is by far the largest single study to assess the effects of ApoE genotypes on lipid levels and inflammatory markers, it may lack statistical power to detect associations with CVD or RA disease severity. Specifically designed large-scale longitudinal studies are required to confirm/refute our findings (e.g., longitudinal data collection, measurement of postprandial lipid levels ${ }^{59}$ ).

We found no differences in the genotypic or allelic fre- 
Table 4. Multivariate analysis demonstrating associations of lipid measures and inflammatory markers with the ApoE genotypes. Bold text indicates statistically significant result $(\mathrm{p}<0.05)$.



Crude: uncorrected data. Model a: Crude data plus adjustment for age and sex. Model b: Model a plus adjustment for demographics (BMI/smoking status) and markers of disease activity/severity (rheumatoid factor positivity \pm CRP: adjusted for only in lipid models not ESR, CRP, or DAS. Model c: Model b plus adjustment for medications (methotrexate, sulfasalazine, hydroxychloroquine, prednisolone, anti-tumor necrosis factor therapy); BMI: body mass index; LDL: low-density lipoprotein; ApoB: apolipoprotein B; ESR: erythrocyte sedimentation rate; DAS: Disease Activity Score; CRP: C-reactive protein.

quencies of ApoE between patients with RA and local population controls. However, ApoE genotypes appeared to be strong predictors of TC, LDL, CRP, ESR, and DAS in RA. The ApoE gene may prove to be a useful prognostic marker for arthritis and vascular outcomes in RA, and this needs to be elucidated in further longitudinal studies.

\section{REFERENCES}

1. Kitas GD, Erb N. Tackling ischaemic heart disease in rheumatoid arthritis. Rheumatology 2003;42:607-13.

2. Reilly PA, Cosh JA, Maddison PJ, Rasker JJ, Silman AJ. Mortality and survival in rheumatoid arthritis: A 25 year prospective study of 100 patients. Ann Rheum Dis 1990;49:363-9.

3. Van Doornum S, McColl G, Wicks IP. Accelerated atherosclerosis: An extraarticular feature of rheumatoid arthritis? Arthritis Rheum 2002;46:862-73.

4. Panoulas VF, Douglas KM, Millionis HJ, Stavropoulos-Kalinglou A, Nightingale P, Kita MD, et al. Prevalence and associations of hypertension and its control in patients with rheumatoid arthritis. Rheumatology 2007;46:1477-82.
5. Panoulas VF, Metsios GS, Pace AV, John H, Treharne GJ, Banks MJ, et al. Hypertension in rheumatoid arthritis. Rheumatology 2008;47:1286-98.

6. Toms TE, Symmons DP, Kitas GD. Dyslipidaemia in rheumatoid arthritis: the role of inflammation, drugs, lifestyle and genetic factors. Curr Vasc Pharmacol 2010;8:301-26.

7. Stavropoulos-Kalinoglou A, Metsios GS, Koutedakis Y, Nevill AM, Douglas KM, Jamurtas A, et al. Redefining overweight and obesity in rheumatoid arthritis patients. Ann Rheum Dis 2007;66:1316-21.

8. Stavropoulos-Kalinoglou A, Metsios GS, Panoulas VF, Douglas KM, Nevill AM, Jamurtas AZ, et al. Associations of obesity with modifiable risk factors for the development of cardiovascular disease in patients with rheumatoid arthritis. Ann Rheum Dis 2009;68:242-5.

9. Metsios GS, Stavropoulos-Kalinoglou A, Panoulas VF, Wilson M, Nevill AM, Koutedakis Y, et al. Association of physical inactivity with increased cardiovascular risk in patients with rheumatoid arthritis. Eur J Cardiovasc Prev Rehabil 2009;16:188-94.

10. Stevens RJ, Douglas KM, Saratzis AN, Kitas GD. Inflammation and atherosclerosis in rheumatoid arthritis. Expert Rev Mol Med 2005;7:1-24.

11. Lee YH, Choi SJ, Ji JD, Seo HS, Song GG. Lipoprotein (a) and Personal non-commercial use only. The Journal of Rheumatology Copyright $\subset$ 2012. All rights reserved. 
lipids in relation to inflammation in rheumatoid arthritis. Clin Rheumatol 2000;19:324-5.

12. Seriolo B, Paolino S, Sulli A, Fasciolo D, Cutolo M. Effects of anti-TNF-alpha treatment on lipid profile in patients with active rheumatoid arthritis. Ann NY Acad Sci 2006;1069:414-9.

13. Svenson KL, Lithell H, Hallgren R, Selinus I, Vessby B. Serum lipoprotein in active rheumatoid arthritis and other chronic inflammatory arthritides. I. Relativity to inflammatory activity. Arch Intern Med 1987;147:1912-6.

14. Dursunoglu D, Evrengul H, Polat B, Tanriverdi H, Cobankara V, Kaftan A, et al. Lp(a) lipoprotein and lipids in patients with rheumatoid arthritis: serum levels and relationship to inflammation. Rheumatol Int 2005;25:241-5.

15. Georgiadis AN, Papavasiliou EC, Lourida ES, Alamanos Y, Kostara $\mathrm{C}$, Tselepis $\mathrm{AD}$, et al. Atherogenic lipid profile is a feature characteristic of patients with early rheumatoid arthritis: effect of early treatment - a prospective, controlled study. Arthritis Res Ther 2006;8:R82.

16. Eichner JE, Dunn ST, Perveen G, Thompson DM, Stewart KE, Stroehla BC. Apolipoprotein E polymorphism and cardiovascular disease: A HuGE review. Am J Epidemiol 2002;155:487-95.

17. Boekholdt SM, Sacks FM, Jukema JW, Shepherd J, Freeman DJ, McMahon AD, et al. Cholesterol ester transfer protein TaqIB variant, high density lipoprotein cholesterol levels, cardiovascular risk and efficacy of pravastatin treatment. Individual patient meta-analysis of 13677 subjects. Circulation 2005;111:278-87.

18. Sagoo GS, Tatt I, Salanti G, Butterworth AS, Sarwar N, van Maarle M, et al. Seven lipoprotein lipase gene polymorphisms, lipid fractions and coronary disease: A HuGE association review and meta-analysis. Am J Epidemiol 2008;168:1233-46.

19. Utermann G, Hees M, Steinmetz A. Polymorphism of apolipoprotein $\mathrm{E}$ and occurrence of dysbetalipoproteinemia in man. Nature 1977;269:604-7.

20. Frikke-Schmidt R, Nordestgaard BG, Jensen GB, Steffensen R, Tybjaerg-Hansen A. Genetic variation in ABCA1 predicts ischemic heart disease in the general population. Arterioscler Thromb Vasc Biol 2008;28:180-6.

21. Ordovas JM, Cupples LA, Corella D, Otvos JD, Osgood D, Martinez A, et al. Association of cholesteryl ester transfer protein-TaqIB polymorphism with variations in lipoprotein subclasses and coronary heart disease risk: the Framingham study. Arterioscler Thromb Vasc Biol 2000;20:1323-9.

22. Saha N, Low PS, Kamboh MI. Association of two polymorphisms in the lipoprotein lipase gene with coronary heart disease. Am J Hum Genet 1998;Suppl 1:A209.

23. Begovich AB, Carlton VE, Honigberg LA, Schrodi SJ, Chokkalingam AP, Alexander HC, et al. A missense single-nucleotide polymorphism in a gene encoding a protein tyrosine phosphatase (PTPN22) is associated with rheumatoid arthritis. Am J Hum Genet 2004;75:330-7.

24. Bowes J, Barton A. Recent advances in the genetics of RA susceptibility. Rheumatology 2008;47:399-402.

25. Gregerson PK, Silver J, Winchester RJ. The shared epitope hypothesis. An approach to understanding the molecular genetics of susceptibility to rheumatoid arthritis. Arthritis Rheum 1987;20:1205-13.

26. Orozco G, Alizadeh BZ, Delgado-Vega AM, Gonzalez-Gay MA, Balsa A, Pascual-Salcedo D, et al. Association of STAT4 with rheumatoid arthritis: A replication study in three European populations. Arthritis Rheum 2008;58:1974-80.

27. Plenge RM, Seielstad M, Padyukov L, Lee AT, Remmers EF, Ding B, et al. TRAF1-C5 as a risk locus for rheumatoid arthritis - A genomewide study. N Engl J Med 2007;357:1199-209.

28. Utermann G. Apolipoprotein E polymorphism in health and disease. Am Heart J 1987;113:440.
29. Watanabe T, Egusa G, Okubo M, Yamakido M. The relationship between apolipoprotein E polymorphism, lipid metabolism and ischaemic heart disease. Atherosclerosis 1999;144:19.

30. Song Y, Stampfer MJ, Liu S. Meta-analysis: Apolipoprotein E genotypes and risk for coronary heart disease. Ann Intern Med 2004;141:137-47.

31. Kelly ME, Clay MA, Mistry MJ, Hsieh-Li HM, Harmony JA. Apolipoprotein E inhibition of proliferation of mitogen-activated $\mathrm{T}$ lymphocytes: Production of interleukin 2 with reduced biological activity. Cell Immunol 1994;159:124-39.

32. Lynch JR, Tang W, Wang H, Vitek MP, Bennett ER, Sullivan PM, et al. APOE genotype and an ApoE-mimetic peptide modify the systemic and central nervous system inflammatory response. J Biol Chem 2003;278:48529-33.

33. Mahley RW, Rall SC Jr. Apolipoprotein E: Far more than a lipid transport protein. Annu Rev Genomics Hum Genet 2000;1:507-37.

34. Jofre-Monseny L, Loboda A, Wagner AE, Huebbe P, Boesch-Saadatmandi C, Jozkowicz A, et al. Effects of apoE genotype on macrophage inflammation and heme oxygenase-1 expression. Biochem Biophys Res Commun 2007;357:319-24.

35. Weisgraber KH. Apolipoprotein E: structure-function relationships. Adv Protein Chem 1994;45:249-302.

36. Angelopoulos TJ, Miles MP, Lowndes J, Sivo SA, Seip RL, Pescatello LS, et al. Apolipoprotein E genotype and sex influence C-reactive protein levels regardless of exercise training status. Metabolism 2008;57:1204-10.

37. Marz W, Scharnagl H, Hoffmann MM, Boehm BO, Winkelmann $\mathrm{BR}$. The apolipoprotein E polymorphism is associated with circulating C-reactive protein (the Ludwigshafen Risk and Cardiovascular Health Study). Eur Heart J 2004;25:2109-19.

38. Koenig W, Sund M, Frohlich M, Fischer HG, Lowel H, Doring A, et al. C-Reactive protein, a sensitive marker of inflammation, predicts future risk of coronary heart disease in initially healthy middle-aged men: results from the MONICA (Monitoring Trends and Determinants in Cardiovascular Disease) Augsburg Cohort Study, 1984 to 1992. Circulation 1999;99:237-42.

39. Nurenberg doctors trial: Declaration of Helsinki (1964). BMJ 1996;313:1448-9.

40. Arnett FC, Edworthy SM, Bloch DA, McShane DJ, Fries JF, Cooper NS, et al. The American Rheumatism Association 1987 revised criteria for the classification of rheumatoid arthritis. Arthritis Rheum 1988;31:315-24.

41. Prevoo ML, van 't Hof MA, Kuper HH, van Leeuwen MA, van de Putte LB, van Riel PL. Modified disease activity scores that include twenty-eight-joint counts. Development and validation in a prospective longitudinal study of patients with rheumatoid arthritis. Arthritis Rheum 1995;38:44-8.

42. Kirwan JR, Reeback JS. Stanford Health Assessment Questionnaire modified to assess disability in British patients with rheumatoid arthritis. Br J Rheumatol 1986;25:206-9.

43. Traynor J, Mactier R, Geddes CC, Fox JG. How to measure renal function in clinical practice. BMJ 2006;333:733-7.

44. Panoulas VF, Douglas KM, Milionis HJ, Stavropoulos-Kalinglou A, Nightingale P, Kita MD, et al. Prevalence and associations of hypertension and its control in patients with rheumatoid arthritis. Rheumatology 2007;46:1477-82.

45. Panoulas VF, Douglas KM, Stavropoulos-Kalinoglou A, Metsios GS, Nightingale P, Kita MD, et al. Long-term exposure to medium-dose glucocorticoid therapy associates with hypertension in patients with rheumatoid arthritis. Rheumatology 2008;47:72-5.

46. Hayden S, Bartel AG, Tabesh E, Cassel JC, Tyroler HA, Cornoni $\mathrm{JC}$, et al. Angina pectoris and the Rose questionnaire. Arch Intern Med 1971;128:961-4.

47. Executive Summary of The Third Report of The National Cholesterol Education Program (NCEP) Expert Panel on Detection, 
Evaluation, And Treatment of High Blood Cholesterol In Adults (Adult Treatment Panel III). JAMA 2001;285:2486-97.

48. Alberti KG, Eckel RH, Grundy SM, Zimmet PZ, Cleeman JI, Donato KA, et al. Harmonizing the metabolic syndrome: a joint interim statement of the International Diabetes Federation Task Force on Epidemiology and Prevention; National Heart, Lung, and Blood Institute; American Heart Association; World Heart Federation; International Atherosclerosis Society; and International Association for the Study of Obesity. Circulation 2009;120:1640-5.

49. Barter P, Gotto AM, LaRosa JC, Maroni J, Szarek M, Grundy SM, et al. HDL cholesterol, very low levels of LDL cholesterol, and cardiovascular events. N Engl J Med 2007;357:1301-10.

50. Gordon T, Castelli WP, Hjortland MC, Kannel WB, Dawber TR. High density lipoprotein as a protective factor against coronary heart disease. The Framingham Study. Am J Med 1977;62:707-14.

51. Sharrett AR, Ballantyne CM, Coady SA, Heiss G, Sorlie PD, Catellier D, et al. Coronary heart disease prediction from lipoprotein cholesterol levels, triglycerides, lipoprotein(a), apolipoproteins A-I and B, and HDL density subfractions: The Atherosclerosis Risk in Communities (ARIC) Study. Circulation 2001;104:1108-13.

52. Conroy RM, Pyorala K, Fitzgerald AP, Sans S, Mentotti A, De Backer G, et al. Estimation of ten-year risk of fatal cardiovascular disease in Europe: The SCORE project. Eur Heart J 2003;24:987-1003.
53. Ridker PM, Buring JE, Rifai N, Cook NR. Development and validation of improved algorithms for the assessment of global cardiovascular risk in women: the Reynolds Risk Score. JAMA 2007;297:611-9.

54. Raffai RL, Loeb SM, Weisgraber KH. Apolipoprotein E promotes the regression of atherosclerosis independently of lowering plasma cholesterol levels. Arterioscler Thromb Vasc Biol 2005;25:436-41.

55. Bach-Ngohou K, Nazih H, Nazih-Sanderson F, Zair Y, Le Carrer D, Krempf M, et al. Negative and independent influence of apolipoprotein $\mathrm{E}$ on $\mathrm{C}$-reactive protein (CRP) concentration in obese adults. Potential anti-inflammatory role of apoE in vivo. Int J Obesity 2001;25:1752-8.

56. Golledge J, Biros E, Cooper M, Warrington N, Palmer LJ, Norman $\mathrm{PE}$. Apolipoprotein E genotype is associated with serum C-reactive protein but not abdominal aortic aneurysm. Atherosclerosis 2010;209:481-91.

57. Ukkola O, Kunnari A, Jokela M, Paivansalo M, Kesaniemi YA. ApoE phenotype is associated with inflammatory markers in middle-aged subjects. Inflamm Res 2009;58:54-9.

58. Gafencu AV, Robciuc MR, Fuior E, Zannis VI, Kardassis D, Simionescu M. Inflammatory signaling pathways regulating ApoE gene expression in macrophages. J Biol Chem 2007;282:21776-85

59. Bergeron N, Havel RJ. Prolonged postprandial responses of lipids and apolipoproteins in triglyceride rich lipoproteins of individuals expressing an apolipoprotein epsilon 4 allele. J Clin Invest 1996;97:65-72. 